\title{
On the enhancement of pervaporation properties of plasma-deposited hybrid silica membranes
}

P.H.T. Ngamou (TU/e) J.P. Overbeek (ECN) H.M. van Veen (ECN) J.F. Vente (ECN) P.F. Cuperus (SolSep) M. Creatore (TU/e)

October 2013

ECN-W--13-052 
Cite this: RSC Advances, 2013, 3, 14241

Received 16th April 2013,

Accepted 24th June 2013

DOI: $10.1039 / c 3 r a 41799 a$

www.rsc.org/advances

The separation performance of a polymeric-supported hybrid silica membrane in the dehydration process of a butanol-water mixture at $95{ }^{\circ} \mathrm{C}$ has been enhanced by applying a bias to the substrate during the plasma deposition.

Pervaporation is an emerging membrane technology for the energy-efficient purification of chemicals such as azeotropic and close-boiling point mixtures, which are challenging to separate by conventional thermal techniques. Specific examples include the separation of water from organic solvents and the recovery of organic compounds from aqueous solutions. For the first application, a supported thin film of microporous silica has attracted considerable attention. Within this amorphous material small $\mathrm{Si}-\mathrm{O}$ rings of about $0.3 \mathrm{~nm}$ in diameter are formed, which can easily sieve small molecules such as water with a kinetic diameter of $0.27 \mathrm{~nm}$ from larger ones. ${ }^{1-3}$ However, the low hydrothermal stability limits the application of these $\mathrm{SiO}_{2}$ membranes to a few weeks at the moderate temperature of 95 ${ }^{\circ} \mathrm{C}$. ${ }^{4}$ The $\mathrm{Si}-\mathrm{O}-\mathrm{Si}$ network is hydrolysed and terminal $\mathrm{Si}-\mathrm{OH}$ groups are formed. As a result cracks and large non-selective pores eventually control the membrane behaviour. The modification of the silica matrix with terminal methyl groups $\left(-\mathrm{CH}_{3}\right)$ has been reported to improve the hydrothermal stability up to two years. ${ }^{4}$ Another common approach to improve the hydrothermal stability of silica membranes is the insertion of organic bridging groups such as $\mathrm{Si}-\mathrm{CH}_{2}-\mathrm{CH}_{2}-\mathrm{Si}$ in the silica matrix, as first reported by Castricum et al. ${ }^{5}$ For example, an hydrothermal stability up to 1000 days in the dehydration of $n$-butanol at $150{ }^{\circ} \mathrm{C}$ has been reported for an organosilica membrane prepared by sol-gel condensation of a bridged precursor, 1,2-bis(triethoxysilyl)ethane (BTESE), $\left(\mathrm{C}_{2} \mathrm{H}_{5} \mathrm{O}\right)_{3} \mathrm{Si}-\left(\mathrm{CH}_{2}\right)_{2}-\mathrm{Si}\left(\mathrm{OC}_{2} \mathrm{H}_{5}\right)_{3} \cdot{ }^{6}$ The excellent stability of

\footnotetext{
${ }^{a}$ Department of Applied Physics, Eindhoven University of Technology, $5600 \mathrm{MB}$ Eindhoven, The Netherlands. E-mail: p.h.tchoua.ngamou@tue.nl; m.creatore@tue.nl; Tel: 003140-2474223

${ }^{b}$ ECN, Energy research Centre of the Netherlands, P.O. Box 1, 1755 ZG Petten, The Netherlands

${ }^{c}$ SolSep BV, 7333 NW, Apeldoorn, The Netherlands

$\dagger$ Electronic supplementary information (ESI) available. See DOI: 10.1039/c3ra41799a
}

sol-gel made BTESE-derived organosilica membranes has also been reported for the dehydration of acetic acid. ${ }^{7}$

Cui et al. ${ }^{8}$ compared the properties (Young's modulus, density, adhesion energy) of organosilica films deposited on polymethylmethacrylate (PMMA) by means of atmospheric plasma CVD using three different precursors. The BTESE-derived organosilica film showed the highest Young's modulus and adhesion to the polymeric substrate. Recently, we reported the successful synthesis of BTESE-derived silica membrane by means of the expanding thermal plasma CVD (ETP-CVD). ${ }^{9}$ The obtained polymericsupported silica films showed comparable pervaporation performances of n-butanol water mixture with that of ceramic membranes. One of the advantages of using ETP-CVD for the synthesis of hybrid silica membranes relies in its compatibility with large area deposition and with relative low-cost and thermally sensitive substrates such as polymers. In addition, the composition, structure and mass density of the selective layer can be tailored by adjusting the plasma and deposition parameters ${ }^{9} \mathrm{~A}$ commonly used approach to tailor the density of plasmadeposited films is the control of the substrate temperature. ${ }^{10}$ However, thermally sensitive substrates such as polymers do not allow for a large process window in this respect. An alternative approach is to provide ion bombardment during the growth of the layer, by means of a negative potential applied to the substrate. Generally, an increase in substrate bias induces an increase in ion energy as well as ion flux if a secondary plasma in front of the substrate is generated. As a result, ion-surface interactions such as surface species migration and surface atom displacement, contributing to the material densification can be promoted. However, a high-energy ion bombardment can also be detrimental due to the sputtering. The potential of this strategy in improving material properties has already been demonstrated for silicon nitride $^{11}$ aluminium oxide, ${ }^{12}$ hydrogenated amorphous silicon ${ }^{13}$ and pure silicon dioxide ${ }^{14}$ films deposited by means ETP-CVD.

The objective of this contribution is to demonstrate the impact of ion bombardment in the development of highly water-selective BTESE-derived organosilica membranes made by ETP-CVD. The ion bombardment during the membrane growth was provided by biasing the substrate by means of an external radiofrequency 
(13.56 MHz) power generator. The hybrid silica layer was deposited on a polyamide-imide substrate using the ETP-CVD setup (ESI-1). In this system, an argon plasma, generated in a dc cascaded arc operating in a pressure range of $500 \mathrm{mbar}$ and an arc current of 50 A, expands supersonically through a nozzle in the deposition chamber kept at the pressure of 0.2 mbar. The BTESE vapour flow rate $(4.6 \mathrm{sccm})$ is injected by means of a punctured ring situated at $5 \mathrm{~cm}$ from the nozzle. The film deposition takes place on a substrate situated at $60 \mathrm{~cm}$ from the nozzle and kept at room temperature. The substrate holder is connected to a power supply for the generation of the rf power via an L-type matching network, used for impedance matching. The rf power is varied in the range of 0 to $15 \mathrm{~W}$, corresponding to dc bias voltage in the range of -3 to $-98 \mathrm{~V}$ with respect to the ground. Experimental conditions in respect to the membrane characterization and pervaporation performance evaluation can be found elsewhere. ${ }^{9}$

Under the assumption that all energy supplied to the system is used to accelerate ions and considering that the plasma potential, $V_{\mathrm{p}}$, is close to zero in the ETP technique, the maximum mean kinetic energy, $E_{\mathrm{i}}$, of the ions arriving at the substrate can be calculated from the following equation: $E_{\mathrm{i}}=e\left|V_{\mathrm{P}}-V_{\mathrm{dc}}\right|$ where, $e$ is the electron charge and $V_{\mathrm{dc}}$ the dc bias voltage. A linearity between the applied rf-power and the bias voltage when using argon- and argon/BTESE-fed plasmas was observed (ESI-2). This indicates that all the supplied energy is used to attract ions present in the expanding thermal plasma towards the growing layer. In addition, the higher $\left|V_{\mathrm{dc}}\right|$ developed in argon/BTESE- fed plasma with respect to the bias voltage developed in an argon plasma is supported by the depletion of argon ions by the BTESE molecules through charge exchange reactions, as previously reported. ${ }^{14}$

Table 1 reports the refractive index $(\lambda=633 \mathrm{~nm})$ determined by spectroscopic ellipsometry (SE), the carbon-to-silicon ratio determined by X-ray photoelectron spectroscopy (XPS) and Rutherford back scattering (RBS) and the film density, assessed from the film thickness and the density of $\mathrm{Si}, \mathrm{C}$ and $\mathrm{O}$ atoms (per surface area), for the unbiased and the biased substrate $(-98 \mathrm{~V})$. The refractive index increases from 1.48 to 1.59 at increasing $\left|V_{\mathrm{dc}}\right|$, while the carbon content drastically decreases as shown by XPS and RBS measurements. It is well-known that the microstructure and the carbon content affect the value of the refractive index of transparent insulator thin films such as silicon dioxide. ${ }^{15,16}$ For instance, the carbon content and the porosity have a positive, respectively negative contribution to the refractive index. For the unbiased substrate, the refractive index, i.e. 1.48, is higher than that of the thermal silica, 1.46, indicating the presence of carboncontaining species in the deposited films. The increase of the refractive index with increasing $\left|V_{\mathrm{dc}}\right|$ is indicative of the

Table 1 Carbon-to-silicon ratio (C/Si), refractive index $(n)$ and density $(\rho)$ of plasma deposited organosilica membranes at different bias voltages

\begin{tabular}{lllll}
\hline$\left|V_{\text {bias }}\right|(\mathrm{V})$ & $\mathrm{C} / \mathrm{Si}(\mathrm{XPS})$ & $\mathrm{C} / \mathrm{Si}(\mathrm{RBS})$ & $n$ at $633 \mathrm{~nm}$ & $\rho\left(\mathrm{g} \mathrm{cm}^{-3}\right)$ \\
\hline No bias & 8.5 & 7.7 & 1.48 & 1.04 \\
98 & 2.1 & 2.5 & 1.59 & 1.75
\end{tabular}

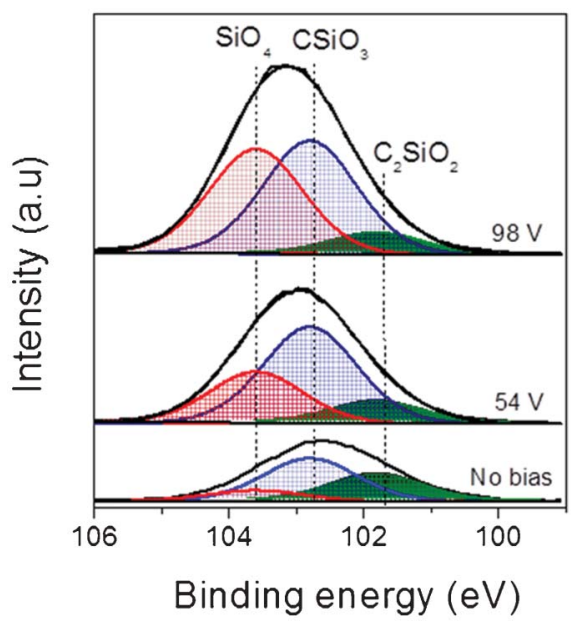

Fig. 1 Deconvolution of the XPS Si2p peak of hybrid silica films deposited for different $\left|V_{\mathrm{dc}}\right|$ values.

densification of the deposited films as noticed by the reduction of the carbon content and the improvement of the mass density.

Fig. 1 shows the Si2p XPS spectra of selected organosilica films deposited at different $\left|V_{\mathrm{dc}}\right|$ values. These Si2p spectra are deconvoluted by means of three contributions referring to $\mathrm{SiO}_{4}$ at $103.6 \mathrm{eV}, \mathrm{CSiO}_{3}$ at $102.8 \mathrm{eV}$ and $\mathrm{C}_{2} \mathrm{SiO}_{2}$ at $101.8 \mathrm{eV} \cdot{ }^{17}$ It can be seen that the peak shifts to higher binding energy values as a consequence of the change in the chemical state of the silicon atom due to shift in chemical environment from carbon-rich to oxygen-rich. The $\mathrm{CSiO}_{3}$ environment is the most represented, showing the hybrid organic-inorganic character of the deposited films. By increasing $\left|V_{\mathrm{dc}}\right|$, the inorganic environment $\left(\mathrm{SiO}_{4}\right)$ increases at the expense of the organic moieties. This behaviour was confirmed by the FTIR analysis (ESI-3). Fig. 2 highlights the decrease in intensity of the vibration band associated to $\mathrm{Si}-$ $\left(\mathrm{CH}_{3}\right)_{x},{ }^{18} \mathrm{Si}-\mathrm{CH}_{2}-\mathrm{CH}_{2}-\mathrm{Si},{ }^{8,19,20} \mathrm{Si}-\mathrm{OCH}_{2} \mathrm{CH}_{3}{ }^{21}$ and $\mathrm{CH}_{x}$ groups in favour of $\mathrm{Si}-\mathrm{O}-\mathrm{Si}$ chain development.

Fig. 3 shows the SEM pictures of the surface of the pristine polyamide-imide (PAI) substrate, the hybrid silica layer deposited with and without bias voltage. The surface of the PAI support is very rough and the presence of small pores of around $8 \mathrm{~nm}$ diameter can be observed. The coverage of the PAI surface is conformal when applying a plasma-deposited layer. A smoothening of the surface is observed when applying a bias voltage $(-98 \mathrm{~V})$ during the deposition, suggesting the development of a denser film, as already observed in Table 1.

The effect of the ion bombardment on the pervaporation performance of the plasma-deposited organosilica layers in the dehydration of $5 \%$ water $/ n$-butanol mixture is reported in Table 2. The results were obtained at $95{ }^{\circ} \mathrm{C}$ after 4 days of continuous operation, allowing a more reliable comparison in term of flux and selectivity. The thickness of the selective hybrid silica layer, determined by means of scanning electron microscopy (Fig. 3) was found to be $230 \mathrm{~nm}$ for the unbiased substrate and $130 \mathrm{~nm}$ when a bias voltage of $98 \mathrm{~V}$ was used. The non-selective pristine polyamide-imide (PAI) support is characterized by a low separation factor of 4.1, corresponding to a water concentration in the 

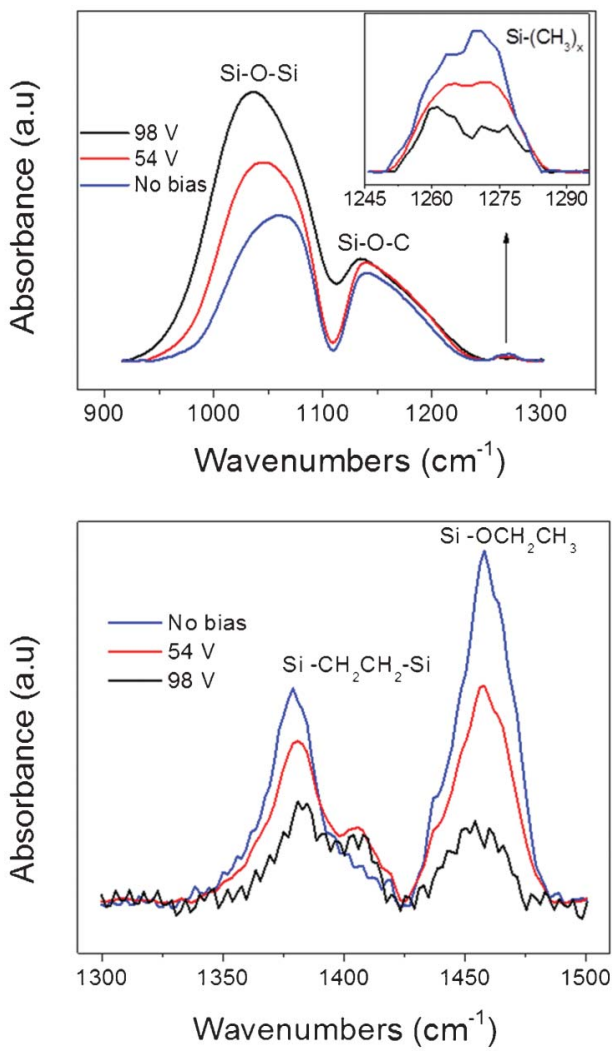

Fig. 2 FTIR spectra of hybrid silica films deposited for different $\left|V_{\text {dc }}\right|$ values, baseline corrected and normalized to the film thickness.

permeate of $17.6 \mathrm{wt} \%$. By biasing the substrate, the separation factor increases from 172 to 950 . The increase in water selectivity with increasing bias can be explained by an improvement of the molecular sieve effect of the deposited layer because of film densification, in agreement with what reported in Table 1. This means that the diffusion of butanol (kinetic diameter of $0.5 \mathrm{~nm}$ ) in the hybrid silica matrix is relative low compared with that of water (kinetic diameter of $0.27 \mathrm{~nm}$ ). In addition to the excellent water
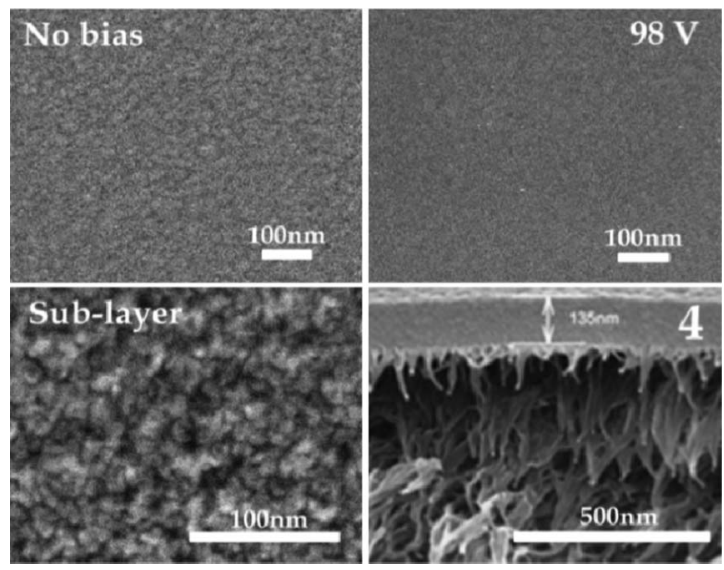

Fig. 3 SEM images of the unbiased film; the biased film (98 V), the polymeric sublayer and cross section of the biased film.
Table 2 Pervaporation properties (water flux, $W_{\mathrm{F}}$, water concentration in the permeate, $W_{\mathrm{P}}$ and separation factor, $\alpha$ ) and contact angle values of plasma deposited organosilica membrane at different bias voltage. PAI refers to the pristine polyamide-imide support

\begin{tabular}{llllr}
\hline$\left|V_{\mathrm{dc}}\right|(\mathrm{V})$ & $W_{\mathrm{F}}\left(\mathrm{g} \mathrm{m} \mathrm{m}^{-2} \mathrm{~h}\right)$ & $W_{\mathrm{P}}(\mathrm{wt} \%)$ & $\theta(\mathrm{deg})$ & $\alpha$ \\
\hline PAI & 4000 & 17.6 & 64 & 4.1 \\
3 & 550 & 90 & 87.9 & 172 \\
98 & 1550 & 98 & 63.2 & 950 \\
\hline
\end{tabular}

selectivity of the RF biased membrane, the water flux was found to increase from 0.55 to $1.55 \mathrm{~kg} \mathrm{~m} \mathrm{~m}^{-2} \mathrm{~h}$ with increasing the bias voltage. For films with almost similar thickness, an increase of the film density is normally associated with a decrease of the permeance due to the increase resistance in the selective layer. However, this is not the case of our plasma-deposited layers. It is most likely that in addition of the size exclusion, the membrane surface-solvent affinity plays an important role in the separation. A possible explanation of this phenomenon can be found in the decreased hydrophobicity as noticed by the behaviour of the water contact angle (Table 2). A less hydrophobic surface favours the adsorption of water which water easily diffuses into the pore of the membrane. In the literature, ${ }^{22}$ the good selectivity of ceramicsupported silica membranes towards the dewatering of alcohols was ascribed to the combined effect of the small pore size and the hydrophilicity of the silica layer.

In summary, applying an $\mathrm{rf}$ bias to a porous polymeric substrate during the deposition enables densification of hybrid silica layers which takes place by formation of siloxane functionalities at the expense of the organic moieties. The densification helps improving the separation performance towards the dehydration of a water-butanol mixture as noticed by the increase in water selectivity and flux.

This work was financially supported by the Dutch Ministry of Economic Affairs/Agentschap NL within the EOS LT program, Project EOS LT 10011763.

\section{References}

1 S. Sommer and T. Melin, Chem. Eng. Sci., 2005, 60, 4509.

2 S. Sommer and T. Melin, Chem. Eng. Process., 2005, 44, 1138.

3 A. W. Verkerk, P. van Male, M. A. G. Vorstman and J. T. F. Keurentjes, Sep. Purif. Technol., 2001, 22-3, 689.

4 J. Campaniello, C. W. R. Engelen, W. G. Haije, P. Pex and J. F. Vente, Chem. Commun., 2004, 834.

5 H. L. Castricum, A. Sah, R. Kreiter, D. H. A. Blank, J. F. Vente and J. E. ten Elshof, Chem. Commun., 2008, 1103.

6 H. M. van Veen, M. D. A. Rietkerk, D. P. Shanahan, M. M. A. van Tuel, R. Kreiter, H. L. Castricum, J. E. ten Elshof and J. F. Vente, J. Membrane Sci., 2011, 380, 124.

7 T. Tsuru, T. Shibata, J. Wang, H. R. Lee, M. Kanezashi and T. Yoshioka, J. Membr. Sci., 2012, 421, 25.

8 L. Cui, A. N. Ranade, M. A. Matos, L. S. Pingree, T. J. Frot, G. Dubois and R. H. Dauskardt, ACS Appl. Mater. Interfaces, 2012, 4, 6587. 
9 P. H. T. Ngamou, J. P. Overbeek, R. Kreiter, H. M. van Veen, J. F. Vente, I. M. Wienk, P. F. Cuperus and M. Creatore, J. Mater. Chem. A, 2013, 1, 5567.

10 M. Creatore, J. C. Cigal, G. M. W. Kroesen and M. C. M. van de Sanden, Thin Solid Films, 2005, 484, 104.

11 F. J. H. van Assche, W. M. M. Kessels, R. Vangheluwe, W. S. Mischke, M. Evers and F. Ab, Thin Solid Films, 2005, 484, 46.

12 I. Volintiru, M. Creatore, J. L. van Hemmen and M. C. M. van de Sanden, Plasma Processes Polym., 2008, 5, 645.

13 A. H. M. Smets, W. M. M. Kessels and M. C. M. van de Sanden, J. Appl. Phys., 2007, 102, 073523.

14 A. Milella, M. Creatore, M. A. Blauw and M. C. M. v. De Sanden, Plasma Processes Polym., 2007, 4, 621.

15 M. Creatore, M. Kilic, K. O’Brien, R. Groenen and M. C. M. van de Sanden, Thin Solid Films, 2003, 427, 137.
16 M. Creatore, S. M. Rieter, Y. Barrell, M. C. M. van de Sanden, R. Vernhes and L. Martinu, Thin Solid Films, 2008, 516, 8547-8553.

17 S. Roualdes, R. Berjoan and J. Durand, Sep. Purif. Technol., 2001, 25, 391.

18 D. D. Burkey and K. K. Gleason, J. Vac. Sci. Technol., A, 2004, 22, 61.

19 A. Dabrowski, M. Barczak, N. V. Stolyarchuk, I. V. Melnyk and Y. L. Zub, Adsorption, 2005, 11, 501.

20 N. V. Stolyarchuk, I. V. Mel'nik, Y. L. Zub, M. Barczak, A. Dabrowski and B. Alonso, Prot. Met. Phys. Chem. Surf., 2009, 45, 169.

21 H. A. Szymanski and R. E. Erickson, Infrared band handbook, 2nd edn, rev. and enl. ed., London, IFI/Plenum, 1970.

22 J. Sekulic, J. E. ten Elshof and D. H. A. Blank, J. Membr. Sci., 2005, 254, 267. 
